\title{
ORIGINAL
}

ARTICLES

\section{Gender Differences in Authorship of Family Medicine Publications, 2002-2017}

Tilden Keller, MHA; Megan Wilson, MD; Kevin Chung, MD; C. Holly Andrilla, MS; David Evans, MD; Jeanne Cawse-Lucas, MD

BACKGROUND AND OBJECTIVES: Representation of women in medicine is increasing, including in academic family medicine. Despite this, women continue to hold a minority of senior faculty and leadership roles. This study examines the trends of women first and senior authorship between 2002 and 2017 in five family medicine journals: Family Medicine, Journal of Family Practice, Journal of the American Board of Family Medicine, Annals of Family Medicine, and American Family Physician. The study also examines gender congruence between first and senior authors and women's membership on editorial boards.

METHODS: We collected and analyzed data on a total of 1,671 original articles published in the five family medicine journals in 2002, 2007, 2012, and 2017. We also examined the gender composition of the journals' editorial boards.

RESULTS: Overall, women first authorship increased significantly from $32.6 \%$ in 2002 to $47.7 \%$ in 2017 . There was no significant difference in women senior authorship or editorial board representation from 2002 to 2017. Both men and women senior authors partnered with women first authors significantly more over the 15 years.

CONCLUSIONS: While there was a statistically significant increase in women first authors between 2002 and 2017, there is still a gap between women's authorship and editorial board representation and their representation within academic family medicine. These gaps could help to explain the continued lack of women represented within senior faculty positions.

(Fam Med. 2021;53(6):416-22.)

doi: 10.22454/FamMed.2021.866524

$\mathbf{W}$ omen face many challenges within the field of medicine, particularly in academic medicine. As in many other professional arenas, gender stereotypes in and out of the workplace, bias, and a lack of mentorship can add barriers to women achieving the same levels of success as men in medicine.

The Association of American Medical Colleges' (AAMC) 2020 publication The State of Women in Academic
Medicine highlighted gender disparities present from medical school applications to senior leadership positions. ${ }^{1}$ After seeing a decline in women applicants to medical school between 2004 and 2014 from $51 \%$ to $46 \%$, the percentage of women applicants rose to $50.9 \%$ in the 20182019 cycle., ${ }^{1,2}$ Women made up $51.6 \%$ of matriculating medical students across the country in $2019 .{ }^{1}$ Within the US medical community, women make up $46 \%$ of resident physicians,
$41 \%$ of medical school faculty, and $35 \%$ of current active physicians. . $^{1,3,4}$

Women also remain underrepresented in leadership positions both in academic and private institutions. ${ }^{1,5}$ According to the AAMC, in 2018 at US medical schools, women represented only $25 \%$ of professors, but $58 \%$ of instructors. ${ }^{4}$ Only $18 \%$ of department chairs and deans within medical schools were women, up slightly from $16 \%$ in $2014 .{ }^{1,2}$

Publication is essential to academic promotion. A growing body of research published in the past 5 years shows that women across specialties continue to be underrepresented as authors of published original articles in peer-reviewed journals. ${ }^{6-27}$ This is referred to as the gender productivity gap. Additional studies show that women encounter more challenges obtaining funding. 10,28-30 The publications of men also have higher perceived impact as measured by a higher h-index, though removal of self-citations eliminates this disparity. ${ }^{31,32}$ Multiple studies in other fields, including otolaryngology, psychiatry, women's health, and dermatology, demonstrate that women are also underrepresented on editorial boards. ${ }^{33-37}$

The percentage of women family physicians rose from $30.5 \%$ in 2002 to $44 \%$ in 2017 , a trend that is likely to continue as $54 \%$ of family

From the University of Washington, Seattle, WA. 
medicine residents were women in 2017., ${ }^{4,38}$ Previous research by Schrager et al published in 2011 showed that within a 3-year time frame from 2006 to 2008 , only one-third of published original research in family medicine was authored by women, despite comprising $44 \%$ of faculty positions. ${ }^{39}$ A 2019 article by Wright et al showed similar findings among first authors published between 2013 and 2017 in the same family medicine journals: $44 \%$ of first authors were women while $49 \%$ of family medicine faculty were women. ${ }^{8}$ In 2020, the Robert Graham Center for Policy Studies in Family Medicine and Primary Care published an assessment of the Center's publications over an 11-year span and demonstrated that $34.5 \%$ studies had a woman first author, and women last authors represented $13.4 \%$ of studies. ${ }^{17}$ Most recently, in 2021, Mieses Malchuk et al demonstrated an increase in the proportion of women last authors in three family medicine publications between 2008-2017, and that women last authors were equally if not more likely to partner with women first authors than their male counterparts. ${ }^{19}$ Jabbarpour et al showed that while the proportion of first and last authors that are women is increasing over the same 10 year period of 2008-2017, editorial board composition remains stagnant. ${ }^{20}$

There are a variety of studies that look at gender and authorship in family medicine, some over a point in time, and some longitudinal over a time period up to 10 years. Many include all articles written during the time period; this research focused only on original articles given the importance placed on original, peer-reviewed work for academic advancement. ${ }^{18-20,22,24,27}$

This study is the first to examine the trajectory of women first authorship, senior authorship, and editorial board membership in family medicine across a 15 -year time period including only original articles for all five of the major American family medicine journals. We chose to examine four points in time over 15 years to see if there were persistent trends. We hypothesized that women's representation within academic journals would steadily increase. With women representing $44 \%$ of family physicians ${ }^{38}$ and $51 \%$ of academic family medicine faculty ${ }^{40}$ in 2017, we hypothesized that women's representation within academic journals would mirror those numbers. We chose to focus on first authors, last authors, and editorial boards because this may also reflect a leadership trajectory for women academic family physicians.

\section{Methods}

We assessed the prevalence of women and gender congruence between first and senior (last listed) authorship of original articles published in five major North American family medicine journals, and the gender distribution in each of the target journals' editorial boards. We included the journals Family Medicine (FM), Journal of Family Practice (JFP), Journal of the American Board of Family Medicine (JABFM), Annals of Family Medicine (AFM), and American Family Physician (AFP). We included all original articles published in the years 2002, 2007, 2012, and 2017 in the data set. Original articles included original research, brief reports, and reviews, and excluded editorials and reflections. Each journal had slightly different nomenclature for different types of articles, so we created a list of included and excluded article type for each journal. For each article, the date of publication (year and month) and the gender of the first and senior author (woman, man, unknown) were collected. Physicians as well as other members of the academic team were included and we did not record the authors' degrees. We did not include articles by a study group with no listed authors. We listed articles with only one author as a first-authored article only. We chose four 1-year time periods to demonstrate a trend but keep the scope of work manageable. We modeled our methods on a similar study in Pediatrics authored by Fishman et al. ${ }^{27}$

We coded gender based on the first names of authors. If the name was indeterminate, we visited institutional websites, social media accounts (such as Doximity and LinkedIn), and internet search engines (such as Google) to code the individual's gender identity from pronouns and/ or appearance. Recognizing that gender is not biological, we chose to use gender and not sex, and are referring to women and men authors rather than female and male. We did not specifically research whether authors identified as transgender or gender nonbinary. One year of articles from one journal were coded by three members of the research team to come to consensus about the accuracy of this process, however we did not calculate interrater reliability.

We obtained the masthead page from one issue per year of each journal from the four target years from their respective editorial teams and reviewed the gender composition of the journals' editorial boards using the same methodology.

We also collected data about the geographic location of the authors' institution. To be classified as an article based in the United States (US article), at least the first or last author had to be from a US institution. We excluded articles for which neither first nor senior author was in the United States.

In academic medicine literature, the last author frequently is considered the senior author and often holds a more senior academic rank. Traditionally this person may offer expertise, support, and possibly mentorship to the first author. Given the potential significance of the relationship, we examined gender concordance of the first and last author.

The University of Washington Institutional Review Board exempted this research and waived the need for informed consent as it used only publicly available databases. 
Statistical Analyses

We coded and stored the data in a Microsoft Excel database and analyzed them using SPSS (v 24.0; IBM Corp, Armonk, New York) to determine the distributions of the gender of first and senior authors in the selected journals. Comparisons between journals, in addition to the effect of senior author gender on first author gender, were examined with $\chi^{2}$ tests. We used the Cochran-Armitage trend test to evaluate for trend over time. We set significance at a $P$ value of .05 .

\section{Results}

We collected data on a total of 1,671 original articles. Of these, no articles were excluded due to inability to determine the gender of either first or senior author. We coded single authors as first author, and these represented $278(16.6 \%)$ of the articles. Table 1 shows the percentages of first and senior authors who were identified as women overall, by journal, and by year of publication. Overall, $40.7 \%(680 / 1,671)$ of the first authors and $43.1 \%(600 / 1,393)$ of the senior authors were women. Analysis of original article authorship in all five journals combined showed increasing representation of women first authors in each of the years studied (Figure 1). The proportion of women first authors in the selected journals combined increased from $32.6 \%(133 / 408)$ in 2002 to $47.7 \%(205 / 430)$ in 2017 ( $P$ for trend <.0001). Analysis of women senior authors demonstrated a statistically nonsignificant increase from $37.7 \%(122 / 324)$ in 2002 to $43.7 \%(163 / 373)$ in 2017 , with a peak of $46.8 \%(162 / 346)$ in $2012(P$ for trend $=.088$ ).

Evaluating each journal independently, the proportion of women first authors across all years was highest in FM and lowest in AFM. There was a statistically significant increase in

Table 1: Representation of Women Among First Authors, Senior Authors, and on Editorial Boards Across Five Family Medicine Journals

\begin{tabular}{|c|c|c|c|c|c|}
\hline \multirow{2}{*}{ Variables } & 2002 & 2007 & 2012 & 2017 & \multirow{2}{*}{ P Value* } \\
\hline & \multicolumn{4}{|c|}{ Number/Total Number (\% } & \\
\hline \multicolumn{6}{|c|}{ Overall } \\
\hline First author & $133 / 408(32.6)$ & $174 / 427(40.8)$ & $168 / 406(41.4)$ & $205 / 430(47.7)$ & $<.0001 *$ \\
\hline Last author & $122 / 324(37.7)$ & $153 / 350(43.7)$ & $162 / 346(46.8)$ & $163 / 373(43.7)$ & .0882 \\
\hline Editorial board & $30 / 108(27.8)$ & $35 / 117(29.1)$ & $32 / 114(28.1)$ & $37 / 114(32.5)$ & .529 \\
\hline \multicolumn{6}{|c|}{ Family Medicine (FM) } \\
\hline First author & 29/74 (39.2) & $30 / 70(42.9)$ & $39 / 72(54.2)$ & $45 / 79(57.0)$ & $.0123 *$ \\
\hline Last author & $21 / 66(31.8)$ & 25/67 (37.3) & $34 / 72(47.2)$ & $36 / 78(46.2)$ & $.0454 *$ \\
\hline Editorial board & $15 / 33(45.5)$ & 13/34 (38.2) & $11 / 31(35.5)$ & $14 / 31(45.2)$ & .9167 \\
\hline \multicolumn{6}{|c|}{ Journal of Family Practice (JFP) } \\
\hline First author & $43 / 120(35.8)$ & 42/98 (42.9) & $38 / 95(40.0)$ & $31 / 87(35.6)$ & .9734 \\
\hline Last author & $61 / 105(58.1)$ & $58 / 91(63.7)$ & $41 / 72(56.9)$ & $27 / 65(41.5)$ & $.0413 *$ \\
\hline Editorial board & $8 / 36(22.2)$ & 6/38 (15.8) & $4 / 25(16.0)$ & $4 / 19(21.1)$ & .8165 \\
\hline \multicolumn{6}{|c|}{ Journal of the American Board of Family Medicine (JABFM) } \\
\hline First author & $15 / 64(23.4)$ & $24 / 55(43.6)$ & 29/81 (35.8) & $50 / 78(64.1)$ & $<.0001 *$ \\
\hline Last author & $15 / 55(27.3)$ & $17 / 49(34.7)$ & $26 / 74(35.1)$ & $31 / 75(41.3)$ & .1105 \\
\hline Editorial board & $1 / 25(4.0)$ & 8/24 (33.3) & $7 / 28(25.0)$ & $7 / 29(24.1)$ & .1561 \\
\hline \multicolumn{6}{|c|}{ Annals of Family Medicine (AFM) } \\
\hline First author & \multirow{3}{*}{ Not in circulation } & $14 / 45(31.1)$ & $11 / 30(36.7)$ & $16 / 34(47.1)$ & .1511 \\
\hline Last author & & $14 / 41(34.2)$ & $7 / 29(24.1)$ & 13/33 (39.4) & .6838 \\
\hline Editorial board & & $2 / 8(25)$ & $5 / 13(38.5)$ & 6/18 (33.3) & .7702 \\
\hline \multicolumn{6}{|c|}{ American Family Physician (AFP) } \\
\hline First author & $46 / 150(30.7)$ & $64 / 159(40.3)$ & $51 / 128(39.8)$ & $63 / 152(41.5)$ & .0742 \\
\hline Last author & $25 / 98(25.5)$ & $39 / 102(38.2)$ & $54 / 99(54.6)$ & $56 / 122(45.9)$ & $.0005 *$ \\
\hline Editorial board & $6 / 14(42.9)$ & $6 / 13(46.2)$ & $5 / 17(29.4)$ & 6/17 (35.3) & .4865 \\
\hline
\end{tabular}

$* P$ value for trend (Cochran-Armitage test) 
Figure 1: Percent of Women First Authors, Senior Authors, and Editorial Board Members Between 2002-2017 ${ }^{40}$

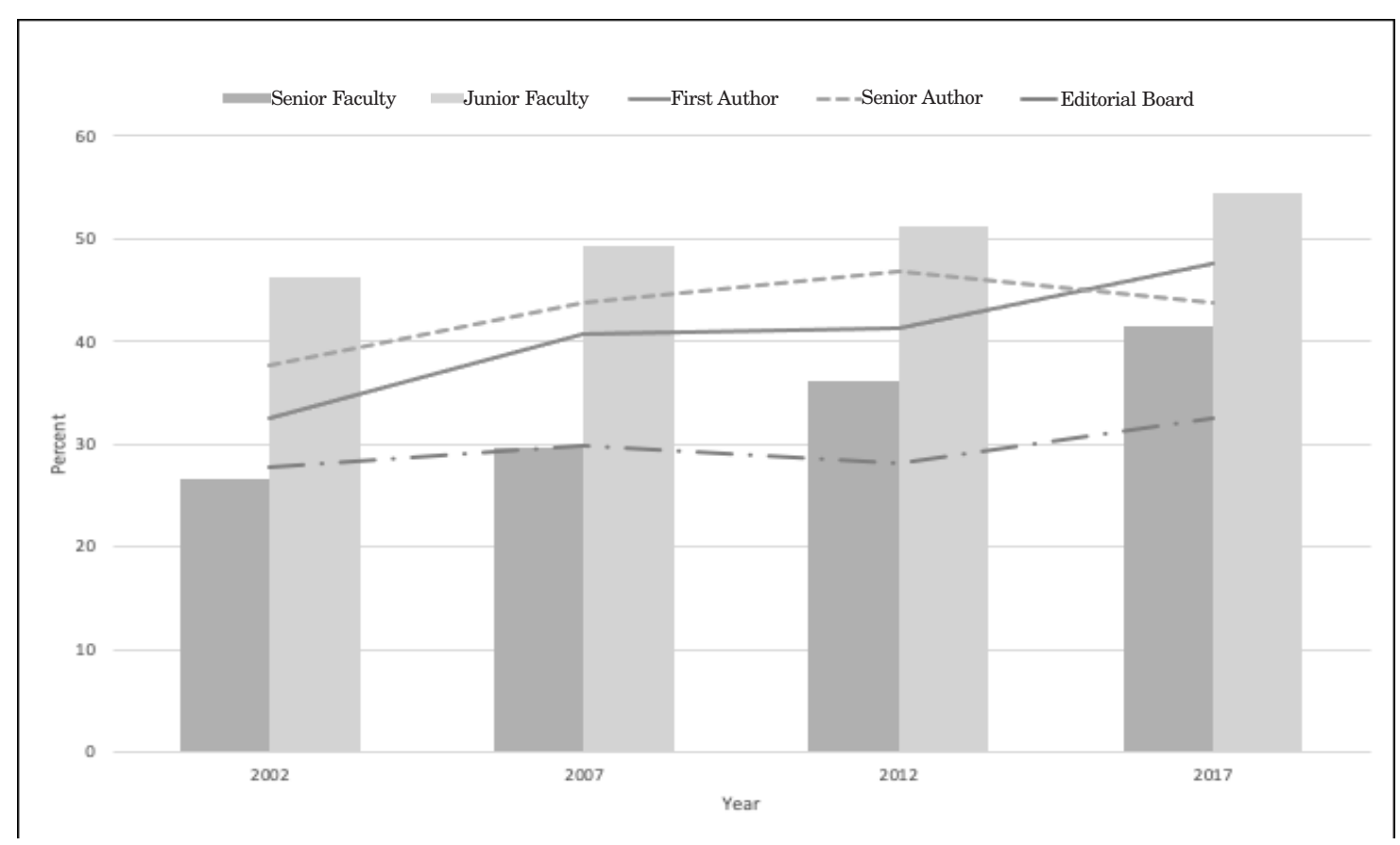

Note: While there was a greater proportion of women senior authors than senior faculty members, there was a smaller proportion of women first authors then junior faculty members. The percentage of women editorial board members was at or below the percent of women senior faculty.

the percentage of women first authors from 2002 to 2017 in FM and JABFM. The proportion of women senior authors across all years was highest in JFP and lowest in AFM. There was a statistically significant increase in the percentage of women senior authors from 2002 to 2017 in FM, JFP, and AFP.

We evaluated the gender distribution of the editorial boards for all five journals for each target year (Table 1, Figure 1). Across all five journals, the representation of women on the editorial boards was $27.8 \%$ (30/108) in 2002 and $32.5 \%$ (37/114) in 2017, though the trend was not statistically significant ( $P$ for trend $=.529$ ). Evaluated independently, none of the journals had a statistically significant trend.

We also examined the proportion of women first authors on articles with women senior authors and men senior authors across all journals (Figure 2). Overall women represented $48.8 \%$ (293/600) of first authors on articles with women senior authors which was significantly greater than the $38.7 \%$ (307/793) of first authors on articles with men senior authors $(P=.0002)$. The proportion of women first authors with women senior authors increased significantly from $39.3 \%$ (48/122) in 2002 to $55.2 \%(90 / 163)$ in 2017 ( $P$ for trend $=.003$ ). The proportion of women first authors with men senior authors also increased significantly from $30.7 \%(62 / 202)$ in 2002 to $47.1 \%$ $(99 / 210)$ in 2017 ( $P$ for trend $=.002$ ).

\section{Discussion}

Women as first authors of original articles in the five academic family medicine journals included in this study rose over the past 15 years, nearly matching representation in academic medicine at $48 \%$ in $2017 .{ }^{40}$ Women as senior authors and members of editorial boards had a slow and not statistically significant increase over the 15-year period, and both continue to lag behind the percentage of women in academic family medicine. Our findings are consistent with other studies, both within family medicine and other specialties. $6.7,16-25,8,26-29,33-37,9-15$ This raises the question of why there are not comparable increases in the percentage of women in leadership. ${ }^{40}$

There are signs of a narrowing gap between the genders within academic family medicine: this study shows better representation in senior authorship, which echoes the AAMC data on academic rank (Figure 1). ${ }^{40}$ While women have not reached equal representation as first authors, senior authors, members of editorial boards, or senior faculty, the overall trend narrows the gender gap. Without publication, promotion is hard to achieve. We hope that a narrowing gender gap in authorship will contribute to a narrowing gap in promotion and leadership. Editorial board 
Figure 2: Collaboration With Women First Authors

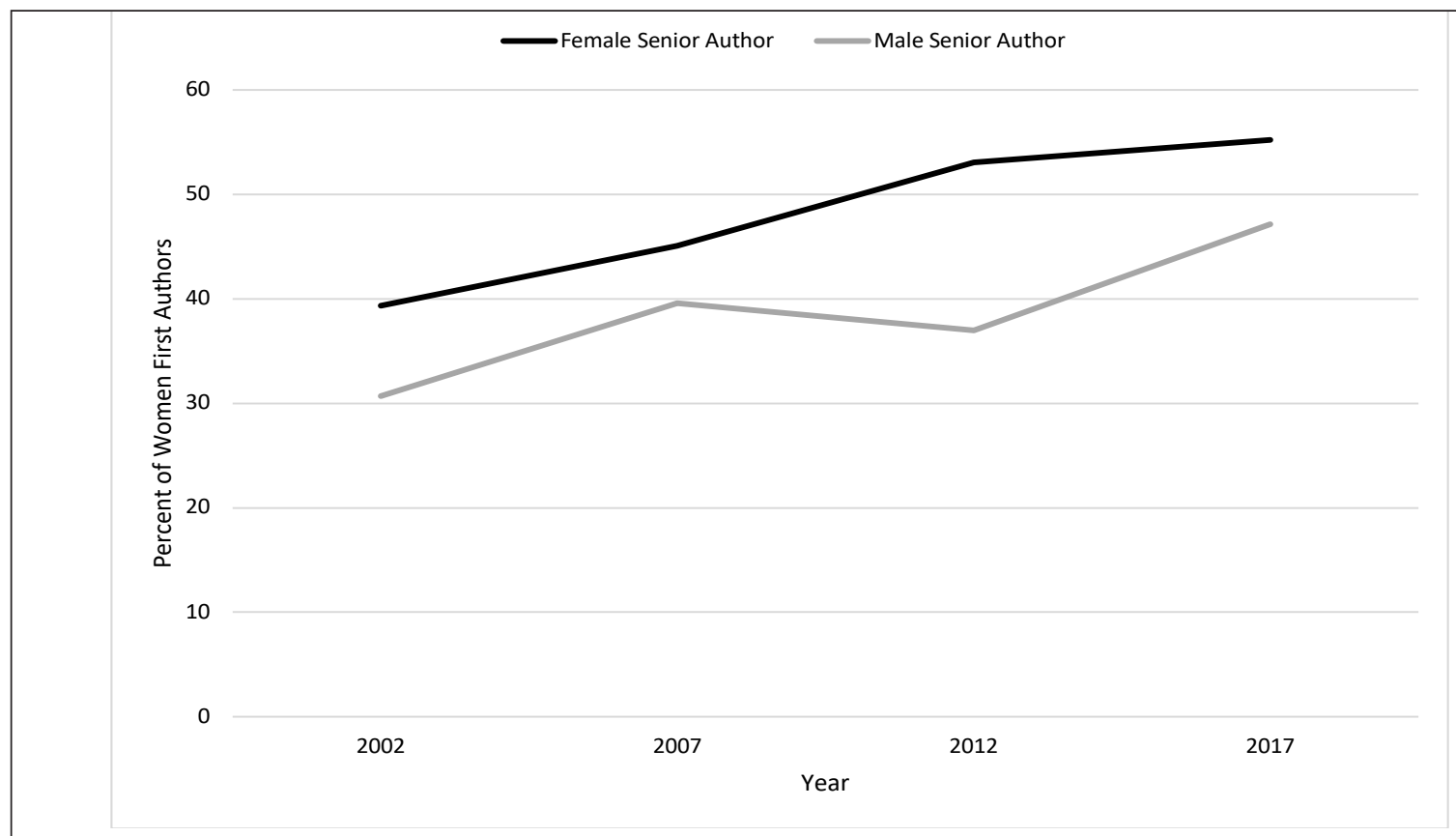

Note: The collaboration of women and men senior authors with women first authors increased significantly over the 15 -year time period studied. There was a statistically significant difference between collaboration by women and men senior authors with women first authors.

representation also falls short of comparisons among authorship and faculty representation at senior and junior ranks. We note that the pattern of significant increases over time among more junior positions (first author, junior faculty rank) are less meaningful if those changes are not carried through up the ranks to senior author, journal editors, or senior faculty rank. Journals and academic departments must encourage equitable representation at every step to publication, including editorial boards.

When analyzing the relationship between first and senior authors, women senior authors are more likely than men senior authors to collaborate with a woman first author. Knowing that senior authors often offer expertise, support, and possibly mentorship to first authors, this gender concordance suggests that women may seek each other out as collaborators. It is unknown whether women senior faculty are more likely to reach out to junior women faculty or junior faculty women are more likely to seek mentorship from women colleagues. Continued efforts need to be made to support faculty collaboration across ranks regardless of gender.

\section{Strengths of the Study}

This study was able to collect a large amount of data across 15 years, leading to a valuable examination of the trends across time within family medicine journals. Trends over time allow more insight into gender representation than a snapshot in time.

\section{Limitation of the Study}

Though this study examined a 15year trend, it did so through four single-year snapshots in time that may result in missed trends. We also chose to evaluate only original articles and did not study the gender breakdown of authorship of other scholarly contributions, such as narrative pieces and editorials. We recognize that while the relationship between senior and junior authors ideally represents one of support or mentorship, it also may be exploitive of junior faculty. ${ }^{41,42}$ We also acknowledge that the first and last authors may consider themselves coequal, particularly in publications with a smaller number of named collaborators. Many family medicine faculty also publish in journals outside of the five that were examined here. Our comparison groups do not represent all of the disciplines that are represented among authors in the five target journals; for example, ABFM diplomates do not include behavioral scientists or researchers and AAMC academic medicine faculty do not include all graduate medical education faculty. We performed this study through a binary gender lens and genders were assigned based on names, appearances, and pronouns used on publicly available websites. This study as well as the data provided by governing bodies does not allow further insight into the representation of transgender and gender nonbinary individuals. The primary research team was composed of two women family medicine physicians and a woman medical 
student interested in family medicine, though several men contributed to this publication. The nature of this study design does not provide insight into causation; further research is required to assess this. For example, the difference in submission rate of original articles by men and women may be a contributing factor, but was not examined in this study.

\section{Future Research}

Areas for continued research include examining the gender impact of editorial board selection process, article submission and review process, and investigating how transgender and gender nonbinary individuals fit into the landscape of authorship and mentorship. To remedy the gender gap in first and senior authorship as well as editorial boards, interventions at all levels will need to be implemented and studied. Finally, obtaining a better understanding of whether publication rates of women and men differ as well as time in rank when applying for similar promotions would allow for a fuller understanding of why women remain underrepresented at senior ranks.

\section{Conclusion}

The data in this study only tell part of the story, and raise questions for future research. Similar to research findings within other specialties, the proportion of women as first authors of original articles within family medicine journals over the last 15 years is rising. However, a gap still exists between the proportion of articles authored by women and the proportion of women within academic family medicine, and the increase in women's representation in senior authorship and editorial boards is halting at best. It is important for editorial boards and academic institutions to make a concerted effort to reduce barriers and increase mentorship to promote more gender equity among authorship, editorial boards, and senior faculty positions.
ACKNOWLEDGMENTS: The authors acknowledge Josie Dolan, Lars Peterson, MD $\mathrm{PhD}$ (ABFM), and Susan Peterson for their assistance gathering data for this study. They also acknowledge Lanie Ross, MD, PhD and Michael Fishman, MD for their guidance as we started this study.

FINANCIAL SUPPORT: Tilden Keller received financial support from the Washington Academy of Family Physicians Foundation and the American Academy of Family Physicians Foundation Summer Student Research Externship.

CORRESPONDING AUTHOR: Address Correspondence to Dr Jeanne Cawse-Lucas, 1959 NE Pacific Street, Box 356391, Seattle, WA 98195. 617-501-3373. Fax: 206-520-2450. cawse@uw.edu.

\section{References}

1. Lautenberger DM, Dandar VM. The state of women in academic medicine, 2018-2019. Assoc Am Med Coll. 2020;1:1-49.

2. Lautenberger DM, Dandar VM, Raexer CL Sloane RA. The state of women in academic medicine: the pipeline and pathway to leadership 2013-2014. Assoc Am Med Coll. 2014;1:117.

3. American Medical Association. 2018 Physician Specialty Data Report. https://www.aamc.org/ data-reports/. Accessed April 13, 2021.

4. Association of American Medical Colleges. 2018 Physician Specialty Data Report. https://www. aamc.org/data-reports/workforce/data/2018physician-specialty-data-report-executivesummary. Accessed April 13, 2021.

5. Jena AB, Olenski AR, Blumenthal DM. Sex differences in physician salary in US public medical schools. JAMA Intern Med. 2016;176(9):1294-1304. doi:10.1001/jamainternmed.2016.3284

6. Hart KL, Frangou S, Perlis RH. Gender trends in authorship in psychiatry journals from 2008 to 2018. Biol Psychiatry. 2019;86(8):639-646. doi:10.1016/j.biopsych.2019.02.010

7. Vranas KC, Ouyang D, Lin A, et al. Gender differences in authorship of critical care literature. American Journal of Respiratory and Critical Care Medicine. 2020;201:A4168. doi:10.1164/ajrccm-conference.2019.199.1_ MeetingAbstracts.A4168

8. Wright KM, Edberg D, Wheat S, Clements DS. Prevalence of women authors in family medicine literature. JAMA Netw Open. 2019;2(11):e1916029. doi:10.1001/jamanetworkopen.2019.16029

9. Brown MA, Erdman MK, Munger AM, Miller AN. Despite growing number of women surgeons, authorship gender disparity in orthopaedic literature persists over 30 years. Clin Orthop Relat Res. 2019;1. doi:10.1097/ CORR.0000000000000849

10. Miller J, Chuba E, Deiner S, DeMaria S Jr, Katz D. Trends in authorship in anesthesiology journals. Anesth Analg. 2019;129(1):306-310 doi:10.1213/ANE.0000000000003949
11. Zayed S, Qu M, Warner A, et al. Are female radiation oncologists underrepresented in the published literature? An analysis of authorship trends over the past decade. Int J Radiat Oncol; 2019. doi:10.1016/j.jjrobp.2019.06.406

12. Branstool TM, Reilly MA, Kivnick A, et al. Analysis of female authorship in two transplant journals: is there a gender gap? J Am Coll Surg. 2019;229(4):e213. doi:10.1016/j.jamcollsurg.2019.08.1411

13. Penn CA, Ebott JA, Larach DB, Hesson AM, Waljee JF, Larach MG. The gender authorship gap in gynecologic oncology research. Gynecol Oncol Rep. 2019;29:83-84. doi:10.1016/j. gore.2019.07.011

14. Menzel LC, Kramer PW, Groneberg DA, Bendels MHK. Gender disparities in authorships of Alzheimer's disease and dementia research articles. J Alzheimers Dis. 2019;70(4):11431152. doi:10.3233/JAD-190216

15. van Doren S, Brida M, Gatzoulis MA, et al. Sex differences in publication volume and quality in congenital heart disease: are women disadvantaged? Open Heart. 2019;6(1):e000882. doi:10.1136/openhrt-2018-000882

16. Farooq A, Sahara K, Muneeb A, et al. Analysis of authorship in hepatopancreaticobiliary surgery: women remain underrepresented. J Gastrointest Surg. 2019:0-6. doi:10.1007/ s11605-019-04340-8

17. Wilkinson E, Coffman M, Huffstetler A, Bazemore A, Jabbarpour Y. Trends in the gender ratio of authorship at the Robert Graham Center. Ann Fam Med. 2020;18(4):341-344. doi:10.1370/afm.2552

18. Kim CY, Sivasundaram L, Trivedi NN, et al. A 46-year analysis of gender trends in academic authorship in orthopaedic sports medicine. J Am Acad Orthop Surg. 2019;27(13):493-501. doi:10.5435/JAAOS-D-18-00669

19. Malchuk AM, Coffman M, Wilkinson E, Jabbarpour Y. Gender concordance of first and senior authors in family medicine journals. Fam Med. 2021;53(2):92-97. doi:10.22454/ FamMed.2021.355251

20. Jabbarpour Y, Wilkinson E, Coffman M, Mieses A. Has female authorship in family medicine research evolved over time? Ann Fam Med. 2020;18(6):496-502. doi:10.1370/afm.2584

21. Lennox MG, Li M, Wang X, Pien LC, Lang DM. Patterns of North American women Authorship in 2 allergy/immunology journals: 1997-2017. J Allergy Clin Immunol Pract. 2019;7(7):21562160. doi:10.1016/j.jaip.2019.03.040

22. Vora M, Kuripla C, Ouyang D, Sing DC. Gender trends in authorship of foot and Ankle academic literature over 24 years. J Foot Ankle Surg. 2019;58(5):898-903. doi:10.1053/j. jfas.2019.01.002

23. Haws BE, Khechen B, Movassaghi K, et al. Authorship trends in spine publications from 2000 to 2015. Spine. 2018;43(17):1225-1230. doi:10.1097/BRS.0000000000002585

24. Pakpoor J, Liu L, Yousem D. A 35-year analysis of sex differences in neurology authorship. Neurology. 2018;90(10):472-475. doi:10.1212/ WNL.0000000000005056 
25. Filardo G, da Graca B, Sass DM, Pollock BD, Smith EB, Martinez MAM. Trends and comparison of female first authorship in high impact medical journals: observational study (1994-2014). BMJ. 2016;352:i847. doi:10.1136/ bmj.i847

26. Yun EJ, Yoon DY, Kim B, et al. Closing the gender gap: increased female authorship in AJR and radiology. AJR Am J Roentgenol. 2015;205(2):237-241. doi:10.2214/AJR.14.14225

27. Fishman M, Williams WA II, Goodman DM, Ross LF. Gender differences in the authorship of original research in pediatric journals, 2001-2016. J Pediatr. 2017;191:244-249.e1. doi:10.1016/j.jpeds.2017.08.044

28. Bennett CL, Raja AS, Kapoor N, et al. Gender differences in faculty rank among academic emergency physicians in the United States. Acad Emerg Med. 2019;26(3):281-285. doi:10.1111/acem.13685

29. Burns KEA, Straus SE, Liu K, Rizvi L, Guyatt G. Gender differences in grant and personnel award funding rates at the Canadian Institutes of Health Research based on research content area: A retrospective analysis. PLoS Med. 2019;16(10):e1002935. doi:10.1371/journal.pmed.1002935

30. Witteman HO, Hendricks M, Straus S, Tannenbaum $\mathrm{C}$. Are gender gaps due to evaluations of the applicant or the science? A natural experiment at a national funding agency. Lancet. 2019;393(10171):531-540. doi:10.1016/S01406736(18)32611-4
31. Astegiano J, Sebastián-González E, Castanho CT. Unravelling the gender productivity gap in science: a meta-analytical review. R Soc Open Sci. 2019;6(6):181566. doi:10.1098/rsos.181566

32. Ahmadi M, Khurshid K, Sanelli PC, et al Influences for gender disparity in academic neuroradiology. AJNR Am J Neuroradiol. 2018;39(1):18-23. doi:10.3174/ajnr.A5443

33. Litvack JR, Wick EH, Whipple ME. Trends in female leadership at high-profile otolaryngology journals, 1997-2017. Laryngoscope. 2019;129(9):2031-2035. doi:10.1002/lary.27707

34. Hafeez DM, Waqas A, Majeed S, et al. Gender distribution in psychiatry journals' editorial boards worldwide. Compr Psychiatry. 2019;94:152119. doi:10.1016/j.comppsych.2019.152119

35. Grinnell M, Higgins S, Yost K, et al. The proportion of male and female editors in women's health journals: A critical analysis and review of the sex gap. Int J Womens Dermatol. 2019;6(1):7-12. doi:10.1016/j.jjwd.2019.11.005

36. Jalilianhasanpour R, Charkhchi P, Mirbolouk M, Yousem DM. Underrepresentation of Women on Radiology Editorial Boards. J Am Coll Radiol. 2019;16(1):115-120. doi:10.1016/j. jacr.2018.08.017

37. Lobl M, Grinnell M, Higgins S, Yost K, Grimes $\mathrm{P}$, Wysong A. Representation of women as editors in dermatology journals: A comprehensive review. Int J Womens Dermatol. 2019;6(1):2024. doi:10.1016/j.ijwd.2019.09.002
38. American Board of Family Medicine. ABFM Certified Family Physicians by Gender. Lexington, KY: American Board of Family Medicine; 2019.

39. Schrager S, Bouwkamp C, Mundt M. Gender and first authorship of papers in family medicine journals 2006-2008. Fam Med. 2011;43(3):155-159.

40. Association of American Medical Colleges (AAMC). AAMC Family Medicine Faculty by Gender:; 2019

41. Bhattacharya S. Authorship issue explained. Indian J Plast Surg. 2010;43(2):233-234. doi:10.4103/0970-0358.73482

42. Sharma H, Verma S. Authorship in biomedical research: A sweet fruit of inspiration or a bitter fruit of trade. Trop Parasitol. 2018;8(2):62-69. doi:10.4103/tp.TP_27_18 